\title{
Memoria en El Salvador, desafios y problemas
}

La memoria, y especialmente el recuerdo del pasado cercano, ha sido sometido a un amplio debate en nuestro país. Por primera vez en la historia salvadoreña el fin de un conflicto no ha supuesto el establecimiento de una historia oficial que narre los acontecimientos a favor de los vencedores. La guerra civil de 11 años terminó con una negociación entre las partes, pero las heridas quedaron en muchos aspectos abiertas. La discusión sobre la oportunidad y la utilidad del recuerdo saltó rápidamente al tapete. La carencia de una facultad de historia en nuestras universidades, la poca relevancia que se le da a la historia como ciencia, nos dejó con frecuencia en una discusión demasiado simplista. La celebración de este Congreso nos abre a un debate más serio, y ojalá del mismo extraigamos las suficientes lecciones como para utilizar adecuadamente nuestros recuerdos.

En primer lugar quiero insistir en que corren entre nosotros una especie de acuerdos generales. Nadie niega en El Salvador afirmaciones como la de que la historia es maestra de la vida, o que la memoria histórica es parte de nuestra identidad. Sin embargo, estas frases flaquean cuando deseamos que la memoria se convierta en acicate de acción para el presente. Se habla de la honestidad de algunos de nuestros próceres o de su sentido del honor, pero ello no incide en una práctica social en la que con frecuencia se honra al mentiroso, o en el necesario cambio de un desarrollo económico montado sobre la corrupción. Incluso, algunos recuerdos históricos parecen utilizarse en la práctica más como justificación del presente que como acicate para el cambio del mismo. Por ejemplo, el recuerdo del expolio colonial, generalmente aceptado como un hecho por todos, se utiliza para decir que al fin salimos de una especie de esclavitud sin someter a crítica las servidumbres del presente. Nuestro himno nacional recuerda que la libertad del país fue conquistada con sangre, pero no invita, ni en su utilización ni en su interpretación común actual, a ampliar hoy los márgenes de libertad.

Si recurriéramos a la división que hace Tzvetan Todorov' entre memoria literal y memoria ejemplar, veríamos con claridad que entre nosotros tiende a dominar la memoria literal. Es decir, ese tipo de memoria que se fija en los acontecimientos del pasado y que desde su pretendida exactitud narrativa y su repetición insistente de lo mismo, impide la planificación del futuro. Pero, incluso, ésta se da en grado mínimo. Nuestra memoria está empequeñecida y en la mayoría de los casos trata de justificar un presente pobre y contradictorio con la igual dignidad humana. Desde el esfuerzo liberal, en el siglo XIX, por reconstruir la memoria histórica de El Salvador, no ha habido otra elaboración seria que trate históricamente de tocar la propia identidad. Olvidando que, como dice el poeta, "la memoria, irreparable, hunde su raíz en lo amargo", los liberales trataron de pintarnos un historia

1. Los abusos de la memoria, Paidós, 2000. 
triunfalista en la que la libertad protagonizaba el pasado salvadoreño y se proyectaba hacia el futuro de un modo casi mesiánico. Más de cien años después, los símbolos oficiales y particulares, así como el discurso, mantienen demasiados elementos triunfalistas. De hecho, más han hecho los poetas que los historiadores oficiales por conservar la identidad y la memoria de los salvadoreños. Los ayes que Roque Dalton dedica a las familias dueñas de los principales periódicos, supuestos cronistas modemos de nuestro pais, utilizan mejor la memoria y mantienen una visión del pasado reciente que todavía tiene eco en el presente: "Ay entonces del grito que no se emitió para dolerse de los hermanos, sino para corromper sus oídos all tiempo que se loaba a su enemigo, ay entonces de la frivolidad con que se apoyó la vigencia del becerro de oro... ay del traslado del crimen hacia los hornbros de los débiles... ay de los soplos al oído del verdugo, ay de las tolerancias, ay de las mentiras matutinas y vespertinas"2.

De todas maneras, el problema de El Salvador no es tanto que nuestra memoria sea literal, que se estanque en el pasado y extienda "el trauma inicial a todos los instantes de la existencia" ". El problema estriba más en que se nos impide recordar. Y en la medida en que se nos priva de la memoria, se nos impide pensar. La abundancia frenética de informaciones, la tergiversación de las historias, la sucesión rápida de los hechos, nos impulsan a vivir al día, a olvidar los problemas y a ahogar la memoria de los acontecimientos importantes en un presente tan frenético como repetitivo. El parloteo constante sobre el presente y el futuro de quienes no quieren tener nada que ver con un pasado incómodo, apenas si nos deja respirar profundo y mantener la reflexión durante el breve lapso que el aire dura en los pulmones.

El olvido, que en muchos aspectos puede ser positivo, cuando es fruto de una selección y un reordenamiento racional y humano de los recuerdos, se convierte en complicidad cuando se le propone como objetivo básico de reconciliación nacional, de reestructuración social, o de cualquier otra tarea histórica.

La memoria ejemplar, como apertura del recuerdo a patrones universales de comportamiento, a modalidades estructurales y racionales de acción, no se tolera en ambientes oficiales. No digamos aquella memoria profética que, inspirada en tradiciones básicas del pasado, quiere denunciar la deshumanización tanto del presente como de las líneas que marcan la dirección del futuro. $Y$ con esta afirmación entramos en el análisis de lo que consideramos un ejemplo particular del debate, en torno a la memoria histórica en El Salvador.

Frente al recuerdo de la guerra y sus atrocidades hay básicamente dos posiciones en El Salvador. La primera, cada vez más matizada, es la que se formuló inicialmente desde el Gobiemo de El Salvador con el lema "perdón y olvido". Bajo esa afirmación tan simple se querían sepultar 11 años en los que se había derrochado tanto dolor, tanta esperanza y tanta pasión encamizada. Como si el perdón consistiera en la trivialización del pasado y generara inmediatamente olvido. Convencidos de la imposibilidad de olvidar, el propio gobierno habla ahora de la necesidad de perdonar, aunque evidentemente no se pueda ni deba olvidar el pasado. Sin embargo, esta tesis en favor del perdón y el recuerdo simultáneo, muestra su complejidad al reducir el recuerdo al ámbito de lo privado. Generalmente quienes mantienen esta posición suelen decir a quienes recuerdan y elaboran propuestas públicas unidas a la memoria, que no han perdonado. $Y$ de alguna manera culpabilizan a las víctimas a causa de su recuerdo, impidiéndoles tanto su legítimo deseo de realización de la justicia como el otorgar a la memoria un rumbo positivo. Porque, en efecto, cuando frente a un asesinato se impide la prosecución de la justicia, se impide, como en los procesos de duelo, que el dolor se cure con mecanismos tanto simbólicos como racionales. Ahora son las víctimas, cuando piden que a través de la justicia sean cerradas sus heridas, las que supuestamente quieren reabrir heridas del pasado molestando la riqueza cómoda de los verdugos impunes.

Los argumentos abundan y no deja de haber quien se inspire en la teoría sicoanalítica para decir que el recuerdo de los acontecimientos duros y crueles del pasado debe confinarse al olvido por simple sanidad mental. Olvidando que la teoría sicoanalítica maneja los acontecimientos traumáticos del pasado con el objetivo de hacerlos conscientes

2. Roque Dalton, Poemas clandestinos, San Salvador: UCA Editores, 1999.

3. T. Todorov, o.c. 
y claros, para después poder iniciar un proceso de reacomodación en el presente que suprima la peligrosa influencia del pasado en la acción actual desde el ámbito de la inconsciencia o del trauma tensionante e irremediable.

Cuando, en algunos momentos, se han llevado a cabo intentos de reactivar la justicia en torno a acontecimientos del pasado, incluso han llovido las acusaciones que insisten en una pérfida valoración desigual de las personas. Sólo, nos dicen estos nuevos partidarios del olvido, si se pudiera hacer justicia a todas las víctimas, se podría iniciar ética-

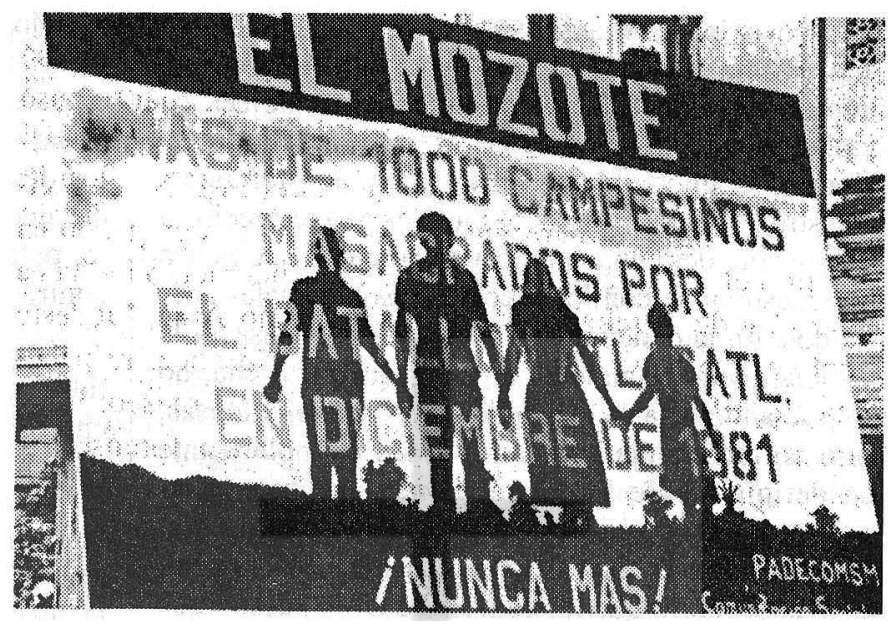
mente un proceso judicial contra los verdugos. De lo contrario, juzgar a unos verdugos y a otros no, nos llevaría a una nueva injusticia contra la víctimas más desposeídas de sus derechos, más olvidadas y a las que nunca se podrá hacer justicia. Es evidente que si este tipo de acción discriminada lo llevara a cabo el Estado con motivaciones exclusivamente políticas, estaríamos de acuerdo. Pero cuando las víctimas son las que reclaman judicialmente, ante la pasividad y obstrucción del Estado, el argumento no sólo pierde su valor, sino que se convierte en justificación de políticas violatorias de los derechos humanos. Son las víctimas las que quieren restablecer la justicia rota en un caso y las que están luchando, al mismo tiempo, para que haya posibilidades de justicia en un sistema que se niega directa y constantemente a ello. Con ello abren camino a que otras víctimas puedan reclamar también sus derechos o que incluso se sientan resarcidas por el carácter simbólico que tienen algunos casos. Casos en los que se conjugan la violación de los derechos, con el mayor conocimiento público del mismo, con la abundancia de pruebas y con el carácter público de violadores de derechos humanos de los acusados.

Más allá de los procesos judiciales, los partidarios del olvido colaboran, incluso, activamente con la negativa a ese tipo de recuerdo simbólico, que restituye la dignidad de las personas. Cuando un grupo de ciudadanos intentó construir un monumento a las víctimas civiles de la guerra, que permitiera el recuerdo de tantas personas anónimas injustamente desposeídas de la vida, que diera la oportunidad a sus familiares de recordarles como personas dignas y de tener un lugar de referencia para el recuerdo que sana las heridas, dicho grupo

sólo encontró la solidaridad de la municipalidad de San Salvador, caracterizada por estar gobernada por ciudadanos con un grado de independencia política notable. El Gobierno y los partidarios del silencio, una vez más, no sólo desecharon la posibilidad de restañar con el recuerdo las ofensas a la dignidad de las personas, sino que mostraron la hipocresía de una posición que al querer unir perdón y recuerdo, privilegia en la práctica únicamente al olvido cuando arroja fuera del ámbito de lo público al recuerdo.

Frente a esta posición de memoria ineficaz, que pretende reducir el recuerdo al ámbito de lo privado, dejando al margen toda incidencia en lo público, diversas instituciones han tratado de recuperar el pasado. Evidentemente no todas lo han hecho con la misma intención. No cabe duda de que hay grupos que no han superado el pasado y que quisieran que el recuerdo de las injusticias los convirtiera en centro del presente. La operación de transferir el crédito y honor de los mártires a sus representantes, en la actualidad, es demasiado bien conocida en la historia como para que nos vayamos a extrañar de que también se dé en nuestras tierras. Sin embargo, entre quienes piden memoria hay generalmente una intencionalidad que nada tiene que ver con la usurpación de honores ajenos.

En primer lugar, se pide que se devuelva su dignidad a las víctimas. Quienes a lo largo de nuestra guerra civil fueron exterminados con crueldad y fueron sometidos al olvido obligatorio a través de la impunidad de sus verdugos, eran personas con la misma dignidad y derechos que cualquier persona. Construir la paz sobre el olvido de la dignidad de las víctimas es la mejor manera de seguir creando vícti- 
mas en el país. $Y$ aunque no se pueda establecer una unilinealidad entre la violencia de la guerra, la impunidad subsiguiente y los terribles indices de violencia actual, es evidente que sí existe una relación entre ambos hechos. La guerra, acostumbrada a destruir niños, ancianos y mujeres, si era preciso a sangre fría, dejó una herencia de crueldad que nunca fue cuestionada con los mecanismos racionales adecuados. En la curación de los traumas del pasado, la justicia quedó totalmente al margen. Y con ella, no sólo abandonada la posibilidad de reparar ofensas, sino también alejada la posibilidad ejemplarizante de definir, desde las instituciones que nos representan a todos, quién es la víctima y quién es el verdugo, donde está el bien y dónde está el mal, cuál es el futuro que queremos y cuál el pasado que queremos dejar verdaderamente en el pasado.

En segundo lugar, el conocimiento de lo sucedido y el análisis certero de sus causas, debe servirnos para no recaer en la repetición de tan terribles crímenes. Y no es malo recordar que estamos hablando de masacres, en las que se ronda el millar de víctimas o de fusilamientos colectivos de una treintena de niños con una edad promedio de 6 años. Recordar el horror tiene su propia influencia disuasiva. Pero analizar las causas del horror puede ayudarnos a planificar el futuro, de tal manera que éste nunca se repita.

En tercer lugar, al ser el pasado lugar de formación de la identidad, el recuerdo de tanta generosidad, vertida en los esfuerzos por superar la guerra civil, nos puede llevar al afianzamiento de valores indispensables para la libre y armónica convivencia. Incluso, en una época como la nuestra, en la que el futuro tiene preeminencia sobre el pasado, la creatividad sobre la memoria, los sucesos que marcaron hitos de humanidad se siguen repitiendo en el recuerdo con tonos muchas veces míticos y festivos. Recuerdos tanto más necesarios en cuanto la ramplonería de la época pide a gritos motivaciones más fuertes que las que puedan darnos los androides convertidos en héroes. Parafraseando a Francisco de Quevedo, es necesario recordar a aquellas personas que entregaron sus ojos a sueños creativos, despejando así la somnolencia de mentes medio adormitadas. Y no sólo recordarlos, sino celebrarlos. La muerte de ciertas víctimas con el paso del tiernpo va abandonando el tinte de dolor que los caracterizó en un primer momento y se van convirtiendo en auténticos acontecimientos festivos. Y ello es así porque, en esas ocasiones, el pasado se convierte en símbolo de lo que está por venir, de lo todavía no realizado, pero que resiste al paso del tiempo como promesa de futuro. $\mathrm{Ha}$ blando de las luchas por restablecer la verdad de los desaparecidos, Todorov, en su artículo ya citado, decía que "la vida ha sucumbido ante la muerte, pero la memoria sale victoriosa en su combate contra la nada".

En ese sentido, que la víctima recobre su identidad a través de la memoria, que quienes derrocharon generosidad sean considerados como verdaderos héroes de humanidad, es motivo de fiesta y de alegría. A pesar de los esfuerzos por reducir a la nada al débil y a la víctima, a pesar de la inquina con que el perseguidor trata de destruir la fama, la resistencia, la identidad y los valores humanos de la persona solidaria y generosa a quien persigue, el recuerdo histórico adecuado hace que el verdugo quede relegado a lo que es, un subproducto de humanidad, y que la víctima sea recordada en su calidad heroica. Que el débil venza al fuerte es siempre motivo de fiesta. Y uno de los símbolos de transformación más poderosos y positivos en la tarea histórica de crear humanidad.

En este sentido, la recuperación de la memoria histórica de la guerra civil salvadoreña cubre varios campos importantes. El primero va ligado a la tarea de hacer justicia. Restablecer la verdad sobre un acontecimiento histórico reciente, en una sociedad que aspira a llamarse democrática, debe ir acompañado por la deducción de responsabilidades. Y esta deducción sólo puede realizarse adecuadamente desde las instancias judiciales. De esta manera, la recuperación de la memoria ayuda no sólo a recordar la magnitud del crimen, sino a evitar con mayor eficacia la posibilidad de la repetición del mismo. Una memoria de un crimen reciente, cometido en connivencia y complicidad de representantes y estructuras estatales, no puede rechazar la judicialización del recuerdo so pena de convertirse en cómplice de los acontecimientos.

En segundo lugar, es de suma importancia retomar ejemplarmente el pasado reciente para extraer de él consecuencias tanto políticas como sociales. Recordar un pasado de impunidad sin luchar contra la impunidad actual, no es más que hipocresía. Establecer la verdad de hechos pretéritos en los que se demuestra la ineficacia funcional de las instituciones democráticas sin combatir la ineficiencia actual, no tendría mayor sentido. La reconciliación que se nos pide con el pasado no 
puede transitar por el olvido de la herencia del mismo que pervive en el presente. Al contrario, sólo si luchamos especialmente contra el desorden estructural que permanece en el presente y que es herencia de una mala organización social que permitió en el pasado terribles crímenes, evitaremos la repetición de los mismos en el futuro más o menos inmediato. Y sin olvidar que luchar contra el crimen del pasado es también luchar contra los criminales, especialmente si éstos continúan presentes en el orden social, en puestos o actividades de prestigio social o de representación estatal o política.

Y finalmente, los crímenes del pasado, con frecuencia, tienen como contrapartida extraordinarios ejemplos de lucha en defensa de valores de humanidad que debemos retomar en el presente. Una sociedad democrática, así como una adecuada regulación de la relación entre personas e instituciones, sólo se mantiene desde la asunción valores. Retomar del pasado los ejemplos en que los valores fueron rubricados por la generosidad, la razón y los sentimientos de humanidad, es indispensable. Porque los conflictos civiles dejan tanto hábitos de impunidad, violencia y arbitrariedad como profundas heridas y rencores, que sólo se pueden curar desde la contemplación positiva de ciertos valores del pasado y desde su aplicación al presente.

¿Es importante la memoria en El Salvador? Sin abusar de ella, sin utilizarla en propio beneficio, sin manipularla como arma arrojadiza que se lanza en una sola dirección, es indispensable para la planificación del futuro. Para evitar los errores del pasado y para construir aquello que la memoria nos dice que quedó inacabado y que es promesa todavía de cara al futuro que nos viene. $Y$ en esta tarea de construir racional y humanamente el futuro, todos somos responsables.

José María Tojeira S.J. Rector de la Universidad Centroamericana "José Simeón Cañas". 